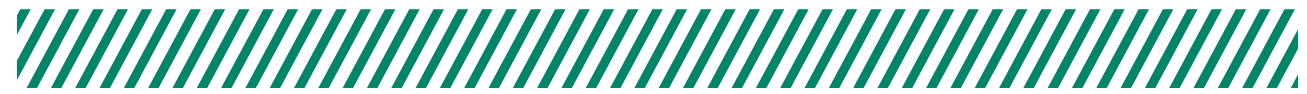

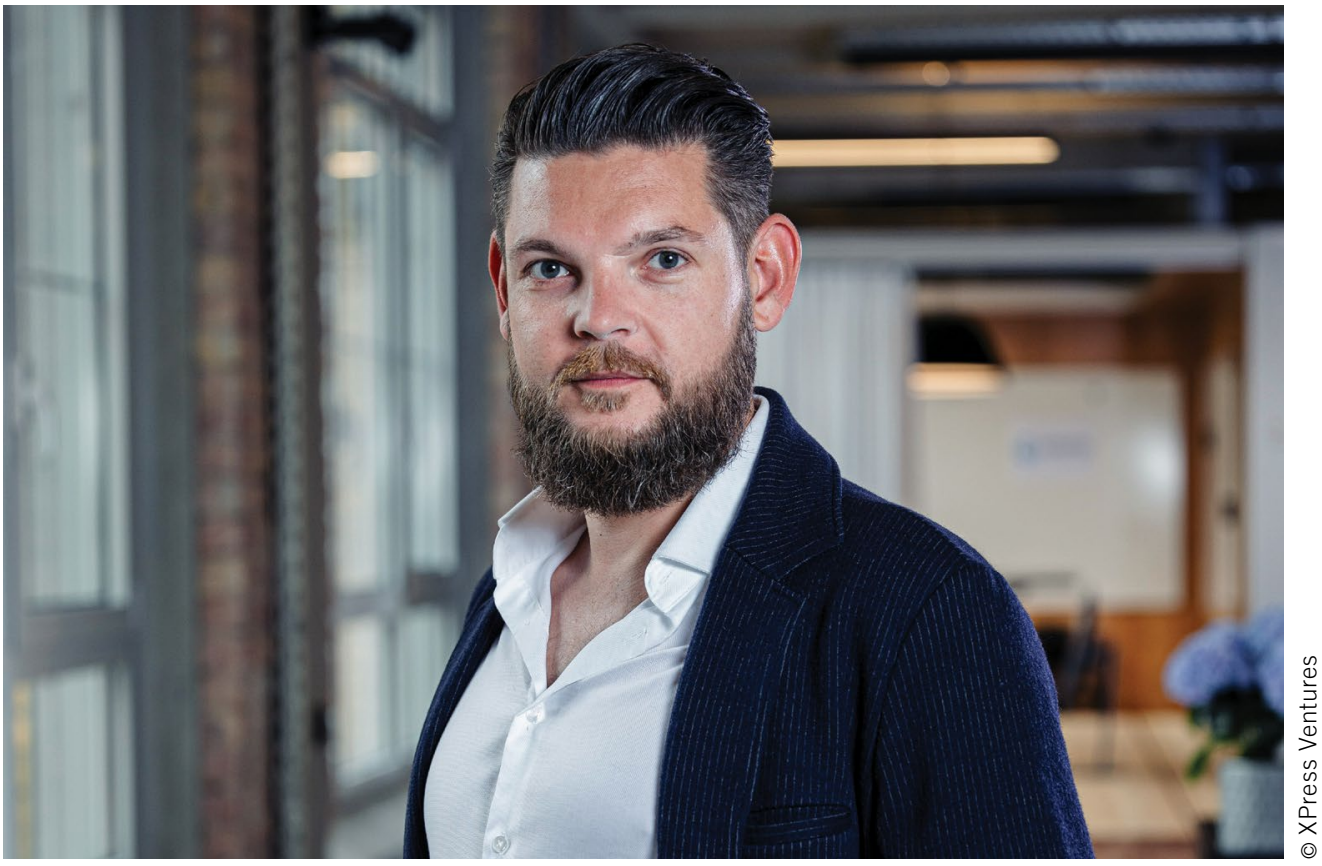

Matthias Friese

Managing Partner at XPress Ventures Fiege Logistik Stiftung \& Co. KG in Berlin

\section{Is Just In Time Coming to an End in the Commercial Vehicle Industry?}

The increase of $36.9 \%$ in commercial vehicles registered in the EU in first half year 2021 compared to the previous year signals a recovery in the commercial vehicle sector. However, depleting inventories are threatening this upturn: According to an ifo survey, $83.4 \%$ of the German automotive industry is currently suffering from a chip shortage. Have we gone too far with the idea of Just In Time (JIT)?

JIT was pioneered by Taiichi Ōno at the Japanese car manufacturer Toyota in the middle of the $20^{\text {th }}$ century. With the idea that parts would be delivered exactly when and where they were needed, Japanese automakers gained an edge over their international competition. JIT took the world by storm, spanning industries from fashion to food production to pharmaceuticals. To cut costs ever further, companies continued to downsize their inventories year after year. These savings meant that they were able to improve their bottom line, and the freed up funds were used to buy back shares instead of investing in production capacities. The best example of possible negative consequences of this development is the continuing shortage of the now ubiquitous microchips.

When the Covid-19 pandemic broke out, the automotive industry in particular found that globalized supply chains could collapse in an instant. The virus crippled factories and global shipping. While some would like to see this crisis as one of many, there is every indication that it is a real turning point. Whether it's the climate crisis, the next territorial conflict or the umpteenth Covid-19 variant - the VUCA (Volatility, Uncertainty, Complexity, Ambiguity; model from management theory to describe the modern world) world has finally caught up with us.

Now more than ever companies need to reevaluate dependencies in supply chains - where does an entire chain hang on a link that can only be procured from one source over long distances? In the future, the cost argument should be weighted more strongly against the accepted risk. Larger warehouses stocked with standard components obviously do not do justice to the ever shorter development cycles of today's vehicles. The dependencies however must be distributed more evenly in order to be able to absorb supply shortages. Local manufacturers can no longer rely on being able to buy critical components such as microchips on the world market at any time. More European chip manufacturing plants are needed, and forward-thinking manufacturers should invest in building them now.

The JIT genie will not return to the bottle, but the commercial vehicle industry would do well to establish resilience as a corporate value going forward. And that can also mean abandoning supposedly indisputable truths. 